Proceedings

\title{
Investigating to Optimal Ratio between Drug and Co-Former in Co-Amorphous Systems ${ }^{+}$
}

\section{Thomas Rades}

Citation: Rades, T. Investigating to Optimal Ratio between Drug and Co-Former in Co-Amorphous Systems. 2020, 78, 27. https:// doi.org/10.3390/IECP2020-08764

Published: 1 December 2020

Publisher's Note: MDPI stays neutral with regard to jurisdictional claims in published maps and institutional affiliations.

Copyright: $@ 2020$ by the authors. Licensee MDPI, Basel, Switzerland. This article is an open access article distributed under the terms and conditions of the Creative Commons Attribution (CC BY) license (http://creativecommons.org/licenses/by/4.0/).
Department of Pharmacy, University of Copenhagen, 2100 Copenhagen, Denmark; thomas.rades@sund.ku.dk + Presented at the 1st International Electronic Conference on Pharmaceutics, online, 1-15 December 2020.

\begin{abstract}
Most new low molecular weight chemical entities in pharmaceutical developments suffer from a low aqueous solubility, making oral delivery challenging. Despite the numerous formulation efforts that can be investigated, research especially on amorphous drugs and formulations appears to be a useful approach. Whilst few drugs can be converted to an amorphous form on their own, due to their physical stability, the use of amorphous solid dispersions, i.e., the dissolution of drug molecules into (amorphous) polymers is increasingly used. However, certain shortcomings of these polymers based amorphous solid dispersions, such as a low drug load and a usually high hygroscopicity, still necessitate the investigation of alternative approaches. One such approach is the use of co-amorphous systems, i.e., the combination of initially crystalline low molecular weight drugs and excipients. Usually, here, a 1:1 molar ratio is used, but this may not be the optimal mixing ratio. In this presentation, work on investigating the optimal ratio between drug and co-former will be presented and critically discussed.
\end{abstract}

Keywords: poor solubility; amorphous; co-amorphous 